Pacific Journal of Mathematics

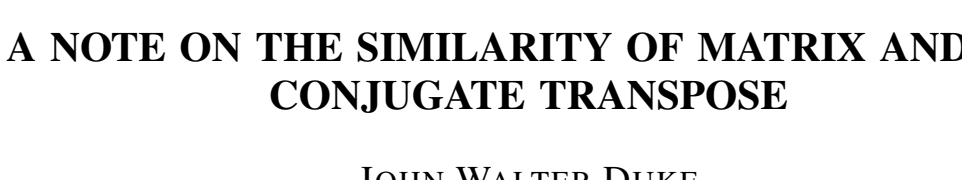




\title{
A NOTE ON THE SIMILARITY OF A MATRIX AND ITS CONJUGATE TRANSPOSE
}

\author{
JoHN W. DUKE
}

It is well-known that each square matrix $A$ over a field is similar to its transpose $A^{T}$ and there exists a nonsingular symmetric matrix $P$ for which $P A^{T}=A P$. The purpose of this note is to show that if $A$ is similar to its conjugate transpose $A^{*}$ then, under certain conditions, there exists a nonsingular Hermitian matrix $Q$ for which $Q A^{*}=A Q$.

Let $f$ be an automorphism of order 2 on a field $F$ and let $K$ be the fixed field of $f$. For each $x$ in $F$, we denote $f(x)$ by $\bar{x}$. If $A=$ $\left(a_{i j}\right)$ is a matrix over $F$, let $A^{*}=\left(b_{i j}\right)$ where $b_{i j}=\overline{a_{j i}}$. A matrix $M$ is called Hermitian (skew-Hermitian) provided $M^{*}=M\left(M^{*}=-M\right)$.

Taussky and Zassenhaus [1] have shown that for each square matrix over a field, there exists a nonsingular symmetric matrix which transforms the given matrix into its transpose. Our main result is

THEOREM 1. Suppose $F$ is an infinite field whose characteristic is different from 2. If a matrix $A$ over $F$ is similar to $A^{*}$, there exists a nonsingular Hermitian matrix $Q$ over $F$ for which $Q A^{*}=$ $A Q$.

We shall utilize the following lemmas in both of which $z$ denotes an element of $F$ which is not in $K$.

Lemma 1. Every element of $F$ can be expressed uniquely in in the form $a+b z$ where both $a$ and $b$ lie in $K$.

Proof. If $c$ belongs to $F$, it is clear that

$$
c=c-(c-\bar{c})(z-\bar{z})^{-1} z+(c-\bar{c})(z-\bar{z})^{-1} z
$$

since $z \neq \bar{z}$. This is the required form since both

$$
a=c-(c-\bar{c})(z-\bar{z})^{-1} z
$$

and

$$
b=(c-\bar{c})(z-\bar{z})^{-1}
$$

lie in $K$. The uniqueness of the expression follows from the fact that $z$ does not belong to $K$. 
LEMMA 2. If $c=r+s z$ and $d=t+u z$ with $r, s, t$, and $u$ in $K$ and $c / \bar{c}=d / \bar{d}$, then $r u=s t$.

Lemma 2 implies that there exists a one-to-one correspondence between $K$ and the set of all elements $c / \bar{c}$ where $c=r+z$ and $r$ ranges over $K$. If $F$ is infinite, Lemma 1 implies that $K$ is infinite.

Proof of Theorem 1. Suppose $P A^{*}=A P$ with $P$ nonsingular. Since the characteristic of $F$ is not 2, the matrix $P$ can be expressed as the sum of an Hermitian matrix $H$ and a skew-Hermitian matrix S. Hence $H A^{*}=A H$ and it remains to show that $H$ may be chosen nonsingular.

Since $(c P) A^{*}=A(c P)$ for all $c$ in $F$, we want to choose $c$ so that $M=c P+\bar{c} P^{*}$ is nonsingular. The matrix $M$ is nonsingular if and only if $-c / \bar{c}$ is distinct from all of the eigenvalues of $P^{-1} P^{*}$. Since there exist infinitely many values of $-c / \bar{c}$, an element $c$ can be properly chosen and the proof is complete.

In regard to finite fields, we have

THEOREM 2. Suppose $A$ is a square matrix of order $n$ over a field $F$ whose characteristic is different from 2 and $P A^{*}=A P$ with $P$ nonsingular. If there exists an element $y$ in $F$ such that $y^{m}$ does not belong to $K$ for $1 \leqq m \leqq n+1$, there exists a nonsingular Hermitian matrix $Q$ for which $Q A^{*}=A Q$.

Proof. Utilizing the same decomposition of $P$ as in the proof of Theorem 1, it is sufficient to show there exists an element $c$ in $F$ such that $c P+\bar{c} P^{*}$ is nonsingular. For $c$ nonzero, $c P+\bar{c} P^{*}$ is nonsingular if and only if $-\bar{c} / c$ is not an eigenvalue of $P\left(P^{*}\right)^{-1}$. Hence let $k_{1}, k_{2}, \cdots, k_{t}$ be the distinct eigenvalues of $P\left(P^{*}\right)^{-1}$ in $F$ and let

$$
W=\left\{1,-k_{1},-k_{2}, \cdots,-k_{t}\right\} \text {. }
$$

If for each nonzero $x$ in $F$ there exists $k$ in $W$ such that $\bar{x}=k x$, then $k^{r}$ belongs to $W$ for all positive integers $r$ since $\bar{x}^{r}=k^{r} x^{r}$. In particular, for the element $y$ mentioned in the hypothesis of the theorem, $\bar{y}=d y$ for some $d$ in $W$ and hence the elements $d^{i}$, for $1 \leqq$ $i \leqq n+2$, all belong to $W$. Since $W$ contains only $t+1$ elements and $0 \leqq t \leqq n$, it follows that $d^{i}=d^{j}$ for some integers $i$ and $j, i<j$, between 1 and $n+2$, inclusively. Hence $j-i \leqq n+1$ and $d^{j-i}=1$ since $d \neq 0$. Therefore

$$
f\left(y^{j-i}\right)=d^{j-i} y^{j-i}=y^{j-i}
$$

implies $y^{j-i}$ belongs to $K$. This contradiction shows the existence of 
some $c$ in $F$ such that $\bar{c} \neq k c$ for all $k$ in $W$ : hence $c$ does not belong to $K$ and $c P+\bar{c} P^{*}$ is nonsingular as required.

As a simple application of Theorem 2, suppose $F=G F\left(p^{2 s}\right)$ with $p \neq 2$ and let $f(x)=x^{p^{s}}$ for all $x$ in $F$. By considering a generator of the multiplicative group of $F$, one may verify the result for matrices over $F$ of order less than $p^{s}$.

\section{REFERENCE}

1. Olga Taussky and Hans Zassenhaus, On the similarity transformation between a matrix and its transpose, Pacific J. Math. 9 (1959), 893-896.

Received January 3, 1969. This note is included in the author's doctoral dissertation prepared under the direction of Professor Burton W. Jones at the University of Colorado.

Angelo State University

SAN Angelo, Texas 



\section{PACIFIC JOURNAL OF MATHEMATICS}

\section{EDITORS}

\author{
H. ROYDEN \\ Stanford University \\ Stanford, California \\ Richard Pierce \\ University of Washington \\ Seattle, Washington 98105
}

\author{
J. DugundJI \\ Department of Mathematics \\ University of Southern California \\ Los Angeles, California 90007 \\ BASIL GoRDON \\ University of California \\ Los Angeles, California 90024
}

\section{ASSOCIATE EDITORS}
E. F. BECKENBACH
B. H. Neumann
F. WOLF
K. YoSHIDA

\section{SUPPORTING INSTITUTIONS}

\author{
UNIVERSITY OF BRITISH COLUMBIA \\ CALIFORNIA INSTITUTE OF TECHNOLOGY \\ UNIVERSITY OF CALIFORNIA \\ MONTANA STATE UNIVERSITY \\ UNIVERSITY OF NEVADA \\ NEW MEXICO STATE UNIVERSITY \\ OREGON STATE UNIVERSITY \\ UNIVERSITY OF OREGON \\ OSAKA UNIVERSITY \\ UNIVERSITY OF SOUTHERN CALIFORNIA
}

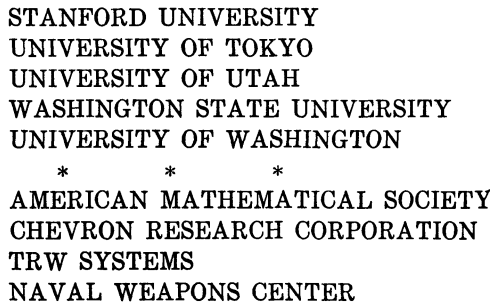

The Supporting Institutions listed above contribute to the cost of publication of this Journal, but they are not owners or publishers and have no responsibility for its content or policies.

Mathematical papers intended for publication in the Pacific Journal of Mathematics should be in typed form or offset-reproduced, double spaced with large margins. Underline Greek letters in red, German in green, and script in blue. The first paragraph or two must be capable of being used separately as a synopsis of the entire paper. It should not contain references to the bibliography. Manuscripts, in duplicate if possible, may be sent to any one of the four editors. Please classify according to the scheme of Math. Rev. 36, 1539-1546. All other communications to the editors should be addressed to the managing editor, Richard Arens, University of California, Los Angeles, California, 90024.

50 reprints are provided free for each article; additional copies may be obtained at cost in multiples of 50 .

The Pacific Journal of Mathematics is published monthly. Effective with Volume 16 the price per volume (3 numbers) is $\$ 8.00$; single issues, $\$ 3.00$. Special price for current issues to individual faculty members of supporting institutions and to individual members of the American Mathematical Society: $\$ 4.00$ per volume; single issues $\$ 1.50$. Back numbers are available.

Subscriptions, orders for back numbers, and changes of address should be sent to Pacific Journal of Mathematics, 103 Highland Boulevard, Berkeley, California, 94708.

PUBLISHED BY PACIFIC JOURNAL OF MATHEMATICS, A NON-PROFIT CORPORATION

Printed at Kokusai Bunken Insatsusha (International Academic Printing Co., Ltd.), 7-17, Fujimi 2-chome, Chiyoda-ku, Tokyo, Japan. 


\section{Pacific Journal of Mathematics}

\section{Vol. 31, No. $2 \quad$ December, 1969}

Efraim Pacillas Armendariz, Quasi-injective modules and stable torsion

classes..........................................

J. Adrian (John) Bondy, On Ulam's conjecture for separable graphs...

Vasily Cateforis and Francis Louis Sandomierski, On commutative rings over which the singular submodule is a direct summand for every module .....

Rafael Van Severen Chacon, Approximation of transformations with continuous

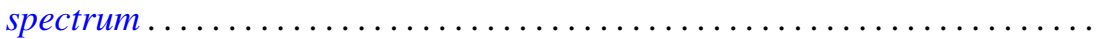

Raymond Frank Dickman and Alan Zame, Functionally compact spaces ...... 303

Ronald George Douglas and Walter Rudin, Approximation by inner

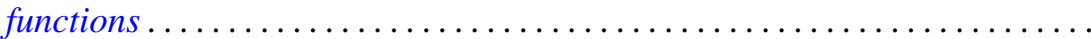

John Walter Duke, A note on the similarity of matrix and its conjugate

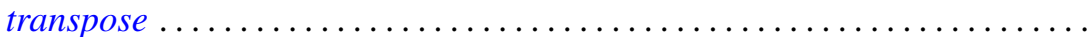

Micheal Neal Dyer and Allan John Sieradski, Coverings of mapping

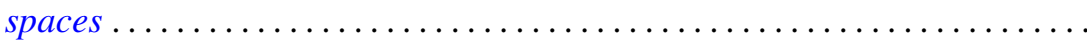

Donald Campbell Dykes, Weakly hypercentral subgroups of finite groups .....

Nancy Dykes, Mappings and realcompact spaces.....................

Edmund H. Feller and Richard Laham Gantos, Completely injective

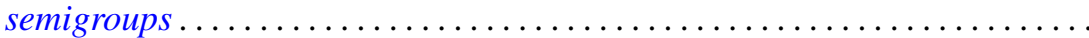

Irving Leonard Glicksberg, Semi-square-summable Fourier-Stieltjes

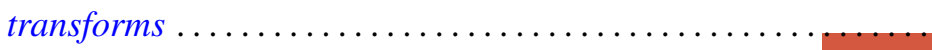

Samuel Irving Goldberg and Kentaro Yano, Integrability of almost cosymplectic structures...

Seymour Haber and Charles Freeman Osgood, On the sum $\sum\langle n \alpha\rangle^{-t}$ and numerical integration ..........................

Sav Roman Harasymiv, Dilations of rapidly decreasing functions ....

William Leonard Harkness and R. Shantaram, Convergence of a sequence of

transformations of distribution functions

Herbert Frederick Kreimer, Jr., A note on the outer Galois theory of rings ...

James Donald Kuelbs, Abstract Wiener spaces and applications to analysis. .

Roland Edwin Larson, Minimal $T_{0}$-spaces and minimal $T_{D}$-spaces...

A. Meir and Ambikeshwar Sharma, On Ilyeff's conjecture .

Isaac Namioka and Robert Ralph Phelps, Tensor products of compact convex sets....

James L. Rovnyak, On the theory of unbounded Toeplitz operators ....

Benjamin L. Schwartz, Infinite self-interchange graphs.......

George Szeto, On the Brauer splitting theorem...

Takayuki Tamura, Semigroups satisfying identity $x y=f(x$,

Kenneth Tolo, Factorizable semigroups .................. 